\title{
Padronização de bioensaios para detecção de compostos alelopáticos e toxicantes ambientais utilizando alface
}

\author{
Mateus Salomão Simões \\ Rafael Hansen Madail * \\ Sandro Barbosa \\ Marina de Lima Nogueira \\ Laboratório de Biotecnologia Ambiental \& Genotoxicidade \\ Instituto de Ciências da Natureza, Universidade Federal de Alfenas \\ Rua Gabriel Monteiro da Silva, 700, prédio V, sala V 003 \\ CEP 37130-000, Alfenas - MG, Brasil \\ * Autor para correspondência \\ rhmadail@yahoo.com.br
}

Submetido em $31 / 10 / 2012$

Aceito para publicação em 06/05/2013

\section{Resumo}

O objetivo deste trabalho foi avaliar diferentes condições experimentais possibilitando a indicação de um protocolo para bioensaios baseado na germinação e crescimento inicial de plântulas utilizando como planta teste a alface (Lactuca sativa L.) cv. Grand Rapids, de forma a fornecer subsídios para padronização de ensaios com substâncias químicas diversas como aleloquímicos ou agentes toxicantes ambientais. Foram realizados os testes: tempo de germinação, temperatura, luminosidade, volume de solução e tamanho da placa de Petri. Para cada teste (exceto tempo de germinação), a influência causada pelas condições averiguadas foi determinada por meio de variáveis de percentagem de germinação, índice de velocidade de germinação, comprimento de raiz, biomassa fresca das plântulas e biomassa seca total. Os resultados encontrados mostraram que variações nas metodologias utilizadas alteram os resultados obtidos. Recomenda-se que os bioensaios utilizando Lactuca sativa cv. Grand Rapids sejam realizados por um período mínimo de quatro dias para as avaliações tanto de germinação quanto de crescimento inicial e as condições experimentais compreendam: temperatura de $20^{\circ} \mathrm{C}$, placas iguais ou maiores a $90 \mathrm{~mm}, 0,1 \mathrm{~mL} /$ cipsela de volume de solução, em luz constante ou fotoperíodo de 12 horas.

Palavras-chave: Ensaios vegetais; Fitotoxicidade; Lactuca sativa L.; Padronização

\section{Abstract}

Bioassay standardization for the detection of allelopathic compounds and environmental toxicants using lettuce. The purpose of this study was to assess different experimental conditions to determine a protocol for bioassays based on seed germination and early seedling growth using lettuce (Lactuca sativa L.) cv. Grand Rapids as indicator species. This protocol aims to provide support for the standardization of assays of various chemicals such as allelochemicals and environmental toxicants. The following tests were performed: time of germination, temperature, light, solution volume and Petri dish size. For each test (except for time of germination), the influence of the conditions investigated was determined by the endpoints germination percentage, germination speed index, root length, seedling fresh weight and total dry weight. The results showed that variations in the 
methods altered the results. It is recommended that bioassays using L. sativa L. cv. Grand Rapids be carried out for a minimum period of four days for assessments of both germination and initial growth and that the experimental conditions include a temperature of $20^{\circ} \mathrm{C}, 90-\mathrm{mm}$ Petri dishes or larger, $0.1 \mathrm{~mL}$ cypsela solution, and continuous light or 12-hour photoperiod.

Key words: Lactuca sativa L.; Phytotoxicity; Plant assays; Standardization

\section{Introdução}

Os bioensaios vegetais demonstram grande eficiência tanto no monitoramento de poluentes ambientais quanto na constatação da ação de compostos químicos derivados do metabolismo secundário das plantas (FERREIRA; AQUILA, 2000; MACÍAS et al., 2000; PANDARD et al., 2006). A alface (Lactuca sativa L.) é uma espécie amplamente utilizada como planta teste nesses estudos (SOUZA FILHO et al., 2010; GOMES et al., 2012; RIBEIRO et al., 2012) devido a sua sensibilidade a agentes químicos, rápida germinação, crescimento linear em ampla faixa de variação de $\mathrm{pH}$ e baixa sensibilidade aos potenciais osmóticos (RICE, 1984; ARAÚJO; MONTEIRO, 2005). Cipselas (fruto) de alface permitem que os efeitos fitotóxicos possam ser averiguados por diferentes variáveis como germinação, alongamento de raiz e biomassa vegetal. Além de serem facilmente encontradas no comércio durante o ano todo, a um baixo custo (ŽALTAUSKAITE; ČYPAITE, 2008).

Apesar do amplo uso de bioensaios vegetais na investigação científica, são escassas as publicações que buscam padronizar os procedimentos experimentais nesse tipo de ensaio (MACÍAS et al., 2000). Na literatura são encontrados diversos protocolos, o que poderia fornecer diferentes resultados em função de variações metodológicas aplicadas e nem sempre em resposta aos tratamentos utilizados. Nesse contexto, torna-se necessário a elaboração de um protocolo eficiente e reproduzível, que possa ser empregado rotineiramente em laboratórios que trabalhem com efeitos de substâncias alelopáticas e de agentes químicos toxicantes ao ambiente, a fim de se aperfeiçoar as condições em que os testes são realizados. Souza Filho et al. (2010) revisando as metodologias utilizadas em estudos de alelopatia, destacam as desvantagens de protocolos distintos empregados em bioensaios vegetais. Além disso, os mesmos autores ressaltam a necessidade da uniformidade dos procedimentos destes ensaios, visando melhorar a compreensão dos resultados obtidos em estudos desta natureza.

Sendo assim, o presente trabalho teve por objetivo a elaboração de um protocolo eficiente e reproduzível para bioensaios baseado na germinação e no crescimento inicial de plântulas utilizando como planta teste a alface (cv. Grand Rapids) a fim de difundir o amplo uso desse protocolo em testes com substâncias alelopáticas e agentes químicos ambientais.

\section{Material e Métodos}

O material utilizado como planta teste foram cipselas de alface (Lactuca sativa L.) cv. Grand Rapids. Para analisar as melhores condições de execução dos bioensaios, foram realizados diferentes testes: tempo de germinação, luminosidade, temperatura, tamanho da placa de Petri e volume de solução. Todos esses foram baseados nas Regras para Análise de Sementes (BRASIL, 2009) com adaptações. Nos testes (exceto para tempo de germinação) foram avaliadas as variáveis: percentagem de germinação (PG), comprimento de raiz (CR), biomassa fresca de plântulas (BF), biomassa seca total (BS) e índice de velocidade de germinação (IVG) de acordo com a expressão:

$$
I V G=\left(G_{1} / N_{1}\right)+\left(G_{2} / N_{2}\right)+\ldots+\left(G_{n} / N_{n}\right) \text {, onde }
$$

$\mathrm{G}_{1}=$ número de sementes germinadas na primeira contagem

$\mathrm{N}_{1}=$ número de dias decorridos até a primeira contagem

$\mathrm{G}_{2}=$ número de sementes germinadas na segunda contagem

$\mathrm{N}_{2}=$ número de dias decorridos até a segunda contagem

$\mathrm{n}=$ última contagem 
As cipselas foram distribuídas em placas de Petri de $90 \mathrm{~mm}$ de diâmetro, contendo papel filtro Whatman $\mathrm{n}^{\circ} 2$ embebido em $0,1 \mathrm{ml}$ de água destilada por cipsela e mantidas em câmara de germinação do tipo BOD a $20^{\circ} \mathrm{C}$ com fotoperíodo de 12 horas, exceto quando especificadas condições distintas como descrito nos testes a seguir.

\section{Tempo de germinação}

Foram realizadas avaliações diárias da germinação até a estabilização do número de cipselas germinadas com o objetivo de definir o número mínimo de dias necessário para condução de bioensaio com a cv. Grand Rapids.

\section{Luminosidade}

Testada com base nas recomendações das RAS (BRASIL, 2009) e nos dados mais comuns encontrados na literatura (MENEZES et al., 2000; WANDSCHEER et al., 2011; SILVA et al., 2006), foram avaliados dois fotoperíodos: 12 horas e luz contínua.

\section{Temperatura}

Foram avaliadas as temperaturas de 15 e $20^{\circ} \mathrm{C}$. Essas temperaturas foram escolhidas com base nas recomendações das RAS (BRASIL, 2009) para alface e nos valores mais referenciados na literatura (MENEZES et al., 2000; FRANÇA et al., 2008; RIBEIRO et al., 2012).

\section{Tamanho da placa de Petri}

Testaram-se três tamanhos de placa de Petri com o objetivo de observar a influência da densidade de semeadura sobre a germinação e o crescimento inicial de plântulas. As placas utilizadas foram de 60, 90 e $120 \mathrm{~mm}$ por serem as mais comumente encontradas em trabalhos laboratoriais.

\section{Volume de solução}

Três volumes de água destilada foram testados visando encontrar o volume de solução mais adequado a ser adicionado às placas de Petri para realização dos bioensaios. Estes valores foram baseados nos apresentados por Macías et al. (2000). Foram testados valores que compreendem 0,$05 ; 0,1$ e $0,15 \mathrm{~mL}$ de solução por cipsela, totalizando 2,$5 ; 5$ e $7,5 \mathrm{~mL}$ por placa.

\section{Delineamento experimental e análise estatística}

O delineamento experimental foi inteiramente casualizado com quatro repetições de 50 cipselas de alface, sendo cada parcela experimental uma placa de Petri. Os dados foram submetidos à análise de variância e comparação múltipla de médias pelo teste de Tukey a 5\% de significância. As análises foram realizadas utilizando software SISVAR (FERREIRA, 2003).

\section{Resultados e Discussão}

\section{Teste de tempo de germinação}

A partir do quarto dia foi observada a estabilização do processo germinativo das cipselas de alface. Nesse mesmo período, foi possível realizar as medidas das variáveis de crescimento inicial, uma vez que as estruturas essenciais das plântulas já se apresentavam formadas.

Contagens feitas antes do período em que ocorre a estabilização da germinação podem gerar resultados equivocados, uma vez que o número de cipselas não germinadas nas placas pode ser em função do período de tempo insuficiente para que o processo germinativo ocorra e não em resposta aos tratamentos impostos. $\mathrm{Na}$ literatura são encontradas referências que utilizam Lactuca sativa cv. Grand Rapids como planta teste em bioensaios por períodos inferiores há quatro dias, o que pode subestimar o percentual de cipselas germinadas.

De acordo com as RAS (BRASIL, 2009) é recomendado que as contagens inicial e final para testar a germinação em alface sejam feitas ao quarto e sétimo dias, respectivamente. Porém, a antecipação da avaliação da germinação para quatro dias pode ser desejável em bioensaios de fitotoxicidade, pois além de tornar o bioensaio mais rápido, evita possíveis contaminações e 
ainda reduz o problema de perda de água do substrato, o que pode prejudicar o desempenho do teste, já que manter a umidade constante durante todo o período de condução é fundamental para a uniformidade do procedimento experimental (VANZOLINI; NAKAGAWA, 2007). Recomenda-se, entretanto, que se observem data de análise e vigor (percentagem de germinação) do lote utilizado, uma vez que sementes mais velhas ou pouco vigorosas requerem período maior de estabilização da germinação.

Outra questão crucial para que a realização do teste de germinação gere resultados confiáveis é o estabelecimento de um critério de germinação apropriado para a espécie utilizada. A curvatura geotrópica da radícula pode ser tomada como critério, quando esta atinge a metade do tamanho da semente (FERREIRA; AQUILA, 2000). Outro critério utilizado refere-se à extensão da raiz igual ou superior a 2,0 mm (FERREIRA et al., 2007, GUSMAN et al., 2008; COELHO et al., 2011; RIBEIRO et al., 2012) ou então quando esta apresenta protrusão visível sem utilização de instrumentos (CETNARSKI FILHO; CARVALHO, 2009; CURIEL; MORAES, 2011). Este último foi o critério utilizado no presente trabalho.

\section{Teste de luminosidade}

As cipselas expostas ao fotoperíodo de 24 horas apresentaram maiores médias para o índice de velocidade de germinação (IVG) em relação àquelas expostas ao fotoperíodo de 12 horas. Entretanto, não foram observadas diferenças na percentagem de germinação (PG) para as condições testadas. Nas variáveis de crescimento inicial, somente a biomassa fresca apresentou diferenças significativas, sendo que as maiores médias foram observadas nos tratamentos que utilizaram fotoperíodo de 12 horas. Biomassa seca total e comprimento de raiz não foram influenciados (Tabela 1).

Cipselas de alface são bastante sensíveis às condições ambientais, como luz e temperatura, o que pode acarretar problemas no processo de germinação e atraso no crescimento das plântulas (MENEZES et al., 2000). Segundo as RAS (BRASIL, 2009), a exposição das cipselas de alface a um período de 8 a 16 horas de luz por dia pode ser benéfica e é recomendada a fim de fornecer condições mais propícias para o crescimento das estruturas essenciais das plântulas, facilitando a avaliação e diminuindo as possibilidades de ataque por microrganismos. Entretanto, na literatura são encontrados também trabalhos que fazem o uso de luz constante (PERES et al., 2004; PERES et al., 2009; WANDSCHEER et al., 2011).

Alguns autores como Menezes et al. (2000) descrevem que a luz é fator limitante para a geminação de alface, sendo que a presença de luz permite que as cipselas germinem numa faixa mais ampla de temperatura.

$\mathrm{Na}$ condução dos experimentos realizados nesse trabalho, as duas condições de luminosidade analisadas mostraram-se satisfatórias.

\section{Teste de temperatura}

As duas condições de temperatura avaliadas influenciaram as variáveis estudadas, com exceção da percentagem de germinação (Tabela 2). $\mathrm{O}$ tratamento que utilizou a temperatura de $20^{\circ} \mathrm{C}$ apresentou as maiores médias de IVG, biomassa fresca, biomassa seca total e de comprimento de raiz, indicando que a temperatura de $15^{\circ} \mathrm{C}$ retarda a germinação das cipselas e o crescimento das plântulas, podendo assim comprometer a viabilidade

TABELA 1: Influência do período de luz nas variáveis de germinação e crescimento inicial de alface ${ }^{1}$.

\begin{tabular}{cccccc}
\hline \multirow{2}{*}{ Período de luz (h) } & \multicolumn{5}{c}{ Variáveis $^{\mathbf{2}}$} \\
\cline { 2 - 6 } & PG (\%) & IVG & CR (mm) & BF (g) & BS (g) \\
\hline 12 & $99,5 \mathrm{a}$ & $65,77 \mathrm{~b}$ & $12,80 \mathrm{a}$ & $0,008 \mathrm{a}$ & $0,008 \mathrm{a}$ \\
24 & $97,5 \mathrm{a}$ & $73,35 \mathrm{a}$ & $13,67 \mathrm{a}$ & $0,006 \mathrm{~b}$ & $0,007 \mathrm{a}$ \\
\hline CV $(\%)$ & 1,55 & 6,14 & 34,18 & 27,56 & 7,62 \\
\hline
\end{tabular}

${ }^{1}$ Colunas seguidas por letras distintas diferem entre si pelo teste de Tukey a 5\% de significância. ${ }^{2}$ PG - Percentagem de Germinação, IVG - Índice de Velocidade de Germinação, CR - Comprimento Radicular, BF - Biomassa Fresca de plântulas, BS -Biomassa Seca Total. 
TABELA 2: Influência da temperatura nas variáveis de germinação e crescimento inicial de alface ${ }^{1}$.

\begin{tabular}{cccccc}
\hline \multirow{2}{*}{ Temperatura $\left({ }^{\circ} \mathbf{C}\right)$} & \multicolumn{5}{c}{ Variáveis $^{2}$} \\
\cline { 2 - 6 } & PG $(\%)$ & IVG & CR $(\mathbf{m m})$ & BF $(\mathbf{g})$ & BS $(\mathbf{g})$ \\
\hline 15 & $94 \mathrm{a}$ & $44,24 \mathrm{~b}$ & $7,93 \mathrm{~b}$ & $0,005 \mathrm{~b}$ & $0,007 \mathrm{~b}$ \\
20 & $95 \mathrm{a}$ & $80,70 \mathrm{a}$ & $15,77 \mathrm{a}$ & $0,008 \mathrm{a}$ & $0,008 \mathrm{a}$ \\
\hline $\mathrm{CV}(\%)$ & 1,93 & 4,53 & 19,81 & 21,27 & 5,36 \\
\hline
\end{tabular}

${ }^{1}$ Colunas seguidas por letras distintas diferem entre si pelo teste de Tukey a $5 \%$ de significância. ${ }^{2}$ PG - Percentagem de Germinação, IVG - Índice de Velocidade de Germinação, CR - Comprimento Radicular, BF - Biomassa Fresca de plântulas, BS -Biomassa Seca Total.

do teste feito nessas condições. Esses dados corroboram aqueles obtidos por Menezes et al. (2000) que, ao realizar um estudo com três cultivares de alface, também relataram ser $20^{\circ} \mathrm{C}$ a melhor temperatura.

Diferentes espécies germinam em resposta a limites distintos de temperatura, sendo os valores recomendados para a condução do teste aqueles nos quais se observa maior número de sementes germinadas em menor intervalo de tempo (BRANCALION et al., 2007). Cipselas de alface de diferentes genótipos também podem apresentar diferentes taxas de germinação frente às faixas de temperatura utilizadas (MENEZES et al., 2000). O estabelecimento da temperatura ótima para o processo germinativo é essencial para homogeneizar as condições e os resultados do teste de germinação (BRANCALION et al., 2007). As RAS (BRASIL, 2009) fornecem duas opções de temperatura para o teste de germinação, em Lactuca sativa sendo estas 15 e $20^{\circ} \mathrm{C}$. Entretanto, na literatura podem ser encontrados diversos trabalhos que utilizam também $25^{\circ} \mathrm{C}$ (SALAM; KATO-NOGUCHI 2010; COELHO et al., 2011; WANDSCHEER et al., 2011).

As RAS (BRASIL, 2009) também fazem recomendações para que a temperatura permaneça a mais homogênea possível dentro da câmara de germinação, pois as oscilações de temperatura podem afetar variáveis do processo germinativo e de crescimento, influenciando, principalmente, na velocidade de germinação e no crescimento inicial das plântulas (VANZOLINI; NAKAGAWA, 2007). Sendo assim, é imprescindível que se façam aferições periódicas da temperatura na câmara de germinação.

\section{Teste de placa de Petri}

Os tamanhos das placas de Petri analisadas influenciaram algumas variáveis de germinação e de crescimento das plântulas de alface (Tabela 3). Nas variáveis de germinação, o IVG respondeu positivamente ao aumento do tamanho das placas utilizadas, sendo que nas placas de $120 \mathrm{~mm}$ de diâmetro foram observados os maiores valores, seguidos pelas de $90 \mathrm{~mm}$ e de $60 \mathrm{~mm}$. As plântulas das placas de $60 \mathrm{~mm}$ também produziram menor biomassa fresca comparada aos demais tratamentos e suas medidas de comprimento de raiz foram menores, em relação ao observado nas placas de $120 \mathrm{~mm}$ de diâmetro. Dessa maneira, nas placas menores, observou-se atraso na germinação e redução do crescimento inicial da cultivar avaliada.

Placas menores apresentam área disponível reduzida, estabelecendo limitações para a germinação e crescimento das plântulas. Esse fato pode estar associado

TABELA 3: Influência do tamanho da placa de Petri nas variáveis de germinação e crescimento inicial de alface .

\begin{tabular}{cccccc}
\hline \multirow{2}{*}{ Tamanho $(\mathbf{m m})$} & \multicolumn{5}{c}{ Variáveis $^{\mathbf{2}}$} \\
\cline { 2 - 6 } & PG (\%) & IVG & CR $(\mathbf{m m})$ & BF $(\mathbf{g})$ & BS $(\mathbf{g})$ \\
\hline 60 & $95 \mathrm{a}$ & $48,32 \mathrm{c}$ & $11,17 \mathrm{~b}$ & $0,007 \mathrm{~b}$ & $0,006 \mathrm{a}$ \\
2490 & $95 \mathrm{a}$ & $53,85 \mathrm{~b}$ & $12,32 \mathrm{ab}$ & $0,008 \mathrm{a}$ & $0,007 \mathrm{a}$ \\
120 & $98 \mathrm{a}$ & $60,87 \mathrm{a}$ & $13,24 \mathrm{a}$ & $0,008 \mathrm{a}$ & $0,007 \mathrm{a}$ \\
\hline CV $(\%)$ & 2,16 & 4,58 & 24,97 & 19,56 & 4,98 \\
\hline
\end{tabular}

${ }^{1}$ Colunas seguidas por letras distintas diferem entre si pelo teste de Tukey a $5 \%$ de significância. ${ }^{2}$ PG - Percentagem de Germinação, IVG - Índice de Velocidade de Germinação, CR - Comprimento Radicular, BF - Biomassa Fresca de plântulas, BS -Biomassa Seca Total 
à baixa disponibilidade de oxigênio, principalmente quando o volume de solução adicionado é suficiente para proporcionar uma condição de hipoxia (MACÍAS et al., 2000; SOUZA et al., 2010) ou então, impor barreira física, principalmente à parte aérea que possui gravitropismo negativo (FERREIRA; AQUILA, 2000).

Ressalta-se que o tamanho da placa a ser utilizada em bioensaios, apesar de causar influência na germinação e crescimento das plântulas de alface, é fator dependente de outros, como o número de cipselas e o volume de solução adicionado. Souza Filho et al. (2003) observaram que a intensidade dos efeitos alelopáticos do extrato aquoso de Calopogonium mucunoides responde negativamente ao aumento da densidade das sementes testadas, sugerindo assim que esse fator interfere nos bioensaios. Essa dependência é descrita por Macías et al. (2000), que analisaram a percentagem de germinação em dois tamanhos diferentes de placas e obtiveram melhores resultados em placas de $90 \mathrm{~mm}$ de diâmetro contendo 10 sementes, do que em placas de $140 \mathrm{~mm}$ com 50 sementes, ambas com o mesmo volume de solução (mL/semente).

\section{Teste de volume de solução}

No teste de volume de solução apenas o IVG e a biomassa fresca apresentaram diferenças significativas (Tabela 4).

Os menores valores de IVG foram encontrados nos tratamentos 0,1 e $0,15 \mathrm{~mL} /$ cipsela. Nesses tratamentos, os volumes de água empregados podem ter sido suficientes para reduzir a disponibilidade de oxigênio no interior das placas proporcionando assim condição de hipoxia. Restrições anaeróbicas consistem em fator limitante no processo germinativo e devem ser consideradas como fonte de interferência nos bioensaios (SOUZA et al., 2010). Macías et al. (2000) descrevem relação negativa entre o aumento do volume de solução e a disponibilidade de oxigênio nas placas. Além disso, nas placas contendo 0,15 mL/cipsela observou-se a formação de lâmina de água. As RAS (BRASIL, 2009) indicam que substratos de papel não devem ser umedecidos excessivamente a ponto de formar essa lâmina, já que esse excesso de solução pode acarretar restrição da aeração.

Nas placas que receberam o menor volume de solução $(0,05 \mathrm{~mL} /$ cipsela) foram observados os maiores valores de IVG, possivelmente apresentando maior disponibilidade de oxigênio. Ressalta-se, contudo, que a utilização de volume relativamente reduzido de solução como $0,05 \mathrm{~mL} /$ cipsela pode ocasionar problemas, como o ressecamento do substrato, o que prejudica a viabilidade do experimento (VANZOLINI; NAKAGAWA, 2007).

Ferreira e Aquila (2000), em sua revisão sobre alelopatia discutem metodologias dos bioensaios vegetais mais usuais e apontam algumas medidas que diminuem o problema de perda de umidade nas placas, como a colocação de mais de uma folha de papel filtro em cada placa, vedação das placas utilizando películas plásticas e a introdução de recipientes com água dentro da câmara de germinação. A adição subsequente de água, quando necessária, pode ser adotada para evitar ressecamento, no entanto esta prática deve ser evitada sempre que possível (BRASIL, 2009), pois pode acarretar em placas distintas do mesmo tratamento contendo volumes de solução diferentes, introduzindo assim nova fonte de interferência ao experimento. Além disso, a manipulação das placas pode aumentar o risco de contaminação do teste.

TABELA 4: Influência do volume de solução nas variáveis de germinação e crescimento inicial de alface .

\begin{tabular}{cccccc}
\hline \multirow{2}{*}{ Volume (mL/cipsela) } & \multicolumn{5}{c}{ Variáveis $^{2}$} \\
\cline { 2 - 6 } & PG (\%) & IVG & CR (mm) & BF (g) & BS (g) \\
\hline 0,05 & $94,50 \mathrm{a}$ & $67,76 \mathrm{a}$ & $18,10 \mathrm{a}$ & $0,005 \mathrm{~b}$ & $0,007 \mathrm{a}$ \\
0,10 & $93,50 \mathrm{a}$ & $56,68 \mathrm{~b}$ & $18,84 \mathrm{a}$ & $0,007 \mathrm{a}$ & $0,007 \mathrm{a}$ \\
0,15 & $95,50 \mathrm{a}$ & $56,10 \mathrm{~b}$ & $17,04 \mathrm{a}$ & $0,07 \mathrm{a}$ & $0,007 \mathrm{a}$ \\
\hline CV $(\%)$ & 3,33 & 7,97 & 29,32 & 22,72 & 11,77 \\
\hline
\end{tabular}

${ }^{1}$ Colunas seguidas por letras distintas diferem entre si pelo teste de Tukey a $5 \%$ de significância. ${ }^{2}$ PG - Percentagem de Germinação, IVG - Índice de Velocidade de Germinação, CR - Comprimento Radicular, BF - Bioassa Fresca de plântulas, BS -Biomassa Seca Total 
A biomassa fresca (BF), apresentou maiores valores nos tratamentos de 0,1 e $0,15 \mathrm{~mL} /$ cipsela. Uma possível explicação para esse resultado pode estar associada ao fato de que as cipselas destas placas, no momento da pesagem, possuíam maior disponibilidade hídrica para o seu crescimento em relação as placas com $0,05 \mathrm{~mL} /$ cipsela. Esses resultados mostraram que o conteúdo de água utilizado não provocou influência na percentagem de germinação, mas afetou a biomassa fresca.

Assim, o volume de solução adicionado nas placas de Petri influenciou em variáveis do processo germinativo e de crescimento inicial da cultivar analisada. Dessa maneira, valores intermediários de volume de solução como o de 0,1 $\mathrm{mL} /$ cipsela são indicados para bioensaios utilizando alface como bioteste. Esse volume, apesar de apresentar um IVG menor que o de $0,05 \mathrm{~mL} /$ cipsela, foi suficiente para suprir as necessidades hídricas das plântulas até o último dia de avaliação, e não gerou acúmulo excessivo de água ao redor das cipselas como ocorrido no tratamento de $0,15 \mathrm{~mL} /$ cipsela. É válido ressaltar que a realização de testes préexperimentais para estipular o volume de solução adequado faz-se importante, e pode fornecer informações confiáveis aumentando a eficiência dos bioensaios.

Recomenda-se que os bioensaios utilizando Lactuca sativa L. cv. Grand Rapids sejam realizados por um período mínimo de quatro dias para as avaliações de germinação e crescimento inicial e as condições experimentais compreendam temperatura de $20^{\circ} \mathrm{C}$, placas iguais ou maiores a $90 \mathrm{~mm}$, volume de solução de $0,1 \mathrm{~mL} /$ cipsela, independente do fotoperíodo.

\section{Agradecimentos}

À FAPEMIG pela concessão de bolsa de IC e a CAPES, pelo aporte financeiro e concessão de bolsa PRODOC.

\section{Referências}

ARAÚJO, A. S. F.; MONTEIRO, R. T. R. Plant bioassays to assess toxicity of textile sludge compost. Scientia Agricola, Piracicaba, v. 62, n. 3, p. 286-290, 2005.

BRANCALION, P. H. S.; NOVEMBRE, A. D. L. C.; RODRIGUES, R. R.; CHAMMA, H. M. C. P. Estabelecimento da temperatura ótima para a germinação das sementes de 272 espécies arbóreas nativas do Brasil. Informativo ABRATES, Londrina, v. 17, n. 1-3, p. 55-68, 2007.

BRASIL, MINISTÉRIO DA AGRICULTURA. Regras para análise de sementes. Brasília: Departamento Nacional de Produção Vegetal, 2009. 365 p.

CETNARSKI FILHO, R.; CARVALHO, R. I. N. Massa da amostra, substrato e temperatura para teste de germinação de sementes de Eucalyptus dunnii Maiden. Ciência Florestal, Santa Maria, v. 19, p. 257-265, 2009.

COELHO, M. F. B.; MAIA. S. S. S.; OLIVEIRA, A. K.; DIÓGENES, F. E. P. Atividade alelopática de extrato de sementes de juazeiro. Horticultura Brasileira, Vitória da Conquista, v. 29, n. 1, p. 108-111, 2011.

CURIEL, A. C.; MORAES, C. P. Germinação de Ormosia arborea (Vell.) Harms submetida a diferentes períodos de exposição e concentração de $\mathrm{GA}_{3}$ pós escarificação mecânica. Scientia Plena, São Cristóvão, v. 7, n. 12, p. 1-6, 2011.

FERREIRA, A. G.; AQUILA, M. E. A. Alelopatia: uma área emergente da ecofisiologia. Revista Brasileira de Fisiologia Vegetal, Campinas, v. 12, p. 175-204, 2000.

FERREIRA, D. F. 2003, Programa de análises estatísticas (statistical analysis software) e planejamento de experimentos - SISVAR 5.1 (Build 72). Disponível em <http://www.dex.ufla. br/ danielff/softwares.htm>. Acesso em: 06 setembro 2012.

FERREIRA, M. C.; SOUZA, J. R. P.; FARIA, T. J. Potenciação alelopática de extratos vegetais na germinação e no crescimento inicial de picão-preto e alface. Ciência e Agrotecnologia, Lavras, v. 31, n. 4, p. 1054-1060, 2007.

FRANÇA, A. C.; SOUZA, I. F.; SANTOS , C. C. ; OLIVEIRA, E. Q.; MARTINOTTO, C. Atividades alelopáticas de Nim sobre o crescimento de sorgo, alface e picão-preto. Ciência e Agrotecnologia, Lavras, v. 32, n. 5, p. 1374-1379, 2008.

GOMES, L. S.; SILVA, F. A.; BARBOSA, S.; KUMMROW, F. Ecotoxicity of sludges generated by textile industries: a review. Journal of Brazilian Society of Ecotoxicology, Itajaí, v. 7, n. 1, p. 89-96, 2012.

GUSMAN, G. S.; BITTENCOURT, A. H. C.; VESTENA, S. Alelopatia de Baccharis dracunculifolia DC. sobre a germinação e desenvolvimento de espécies cultivadas. Acta Scientiarum. Biological Sciences, Maringá, v. 30, n. 7, p. 119-125, 2008.

MACÍAS, F. A.; CASTELlANO, D.; MOLINILlO, J. M. G. Search for a standart phytotoxic biossay for allelochemicals. Selection of standard target species. Journal of Agriculture and Food Chemistry, Davis, v. 48, n. 6, p. 2512-2521, 2000.

MENEZES, N. L.; SANTOS, O. S.; NUNES, E. P.; SCHIMIDT, D. Qualidade fisiológica de sementes de alface submetidas a diferentes temperaturas na presença e ausência de luz. Ciência Rural, Santa Maria, v. 30, n. 6, p. 941-945, 2000.

PANDARD, P.; DEVILLERS, J.; CHARISSOU, A. M.; POULSEN, V.; JOURDAIN, M. J.; FÉRARD, J. F.; GRAND, C.; BISPO, A. Selecting a battery of bioassays for ecotoxicological characterization of wastes. Science of the Total Environment, Amsterdam, v. 363, p. 114-125, 2006.

PERES, M. T. L. P.; MAPELI, A. M.; FACCENDA, O.; GOMES, A. T.; HONDA, N. K. Allelopathic potential of orsellinic acid derivatives. Brazilian Archives of Biology and Technology, Curitiba, v. 52, n. 4, p. 1019-1026, 2009. 
PERES, M. T. L. P.; SILVA, L. B.; FACCENDA, O.; HESS, S. C. Potencial alelopático de espécies de Pteridaceae (Pteridophyta). Acta Botanica Brasilica, Feira de Santana, v. 18 n. 4, p. 723-730, 2004.

RIBEIRO, L. O.; BARBOSA, S.; BALIEIRO, F. P.; BEIJO, L. A.; SANTOS, B. R.; GOUVEA, C. M. C. P.; PAIVA, L. V. Fitotoxicidade de extratos foliares de barbatimão [Stryphnodendron adstringes (Mart.) Coville] em bioensaio com alface. Revista Brasileira de Biociências, Porto Alegre, v. 10, n. 2, p. 220-225. 2012.

RICE, E. L. Allelopathy. 2 ed. New York: Academic Press, 1984. $422 \mathrm{p}$.

SALAM, M. A.; KATO-NOGUCHI, H. K. 2010. Evaluation of allelopathic potential of neem (Azadirachta indica. A. Juss) Against seed germination and seedling growth of different test plant species. International Journal of Sustainable Agriculture, Dubai, v. 2, n. 2, p. 20-25, 2010.

SILVA, G. B.; MARTIM, L.; SILVA, C. L.; YOUNG, C. M.; LADEIRA, A. M. Potencial alelopático de espécies arbóreas nativas do Cerrado. Hoehnea, São Paulo, v. 33, n. 3, p. 331-338, 2006.
SOUZA FILHO, A. P. S.; ALVES, S. M.; FIGUEIREDO, F. J. C. Efeitos alelopáticos do calopogônio em função de sua idade e da densidade de sementes da planta receptora. Planta Daninha, Viçosa, v. 21, n. 2, p. 211-218, 2003.

SOUZA FILHO, A. P. S.; GUILHON, G. M. S. P.; SANTOS, L. S. Metodologias empregadas em estudos de avaliação da atividade alelopática em condições de laboratório-Revisão crítica. Planta Daninha, Viçosa, v. 28, n. 3, p. 689-697, 2010.

VANZOLINI, F.; NAKAGAWA, F. Teste de vigor baseados no desempenho de plântulas. Informativo ABRATES, Londrina, v. 17, n. 1-3, p. 76-83, 2007.

WANDSCHEER, A. C. D.; BORELLA, J.; BONATTI, L. C.; PASTORINI, L. H. Atividade alelopática de folhas e pseudofrutos de Hovenia dulcis Thunb. (Rhamnaceae) sobre a germinação de Lactuca sativa L. (Asteraceae). Acta Botanica Brasilica, Feira de Santana, v. 25, n. 1, p. 25-30, 2011.

ŽALTAUSKAITE, J.; ČYPAITE, A. Assessment of landfill leachate toxicity using higher plants. Environmental Research, Engineering and Management, Kaunas, v. 4, n. 46, p. 42-47, 2008 . 